\title{
NOTICIAS
}

\section{JORNADAS MICOLÓGICAS: HONGOS DE LA ESTACIÓN BIOLÓGICA DE TORRETES-FONT ROJA}

\section{J. Juan ${ }^{I}, R$. Garcia ${ }^{2}$ y V. Martínez-Francés ${ }^{I}$}

1 Estación Biológica Torketes-Font Roja (Cigio), Universidad de. Alicante.

E-MalL- Estacion.Tortetespua.es

2 Museo de la Bioduversidad (Cibio), Universidad de Alicante.

\section{INTRODUCCIÓN}

Las Exposiciones Temporales forman parte del conjunto de actividades de divulgación llevadas a cabo por el CIBIO en el Museo de la Biodiversidad. Dado que los hongos son organismos que suscitan un especial interés entre los científicos y aficionados $y$ con el ánimo adquirido por los buenos resultados de la primera edición, se celebraron las II Jornadas Micológicas del Museo de La Biadiversidad entre los dias 19 y el 28 de Noviembre del pasado año 2007. Las jornadas tuvieron como ptincipales objetivos acercar al público el fascinante mundo de los hongos $y$ favorecer el intercambio de conocimientos entre los expertos y los aficionados a la micologia, a través de distintas charlas, actividades $y$ salidas de campo. Se enfatixó en informar, formar y concienciar a la ciudadania sobre la importancia de los hongos, su vital función en los ecosistemas, así como sus cualidades. culinarias y el peligto que conlleva el consumo de alguno de ellos. Ademís, aprovechando las salidas al campo y los talleres, se inició un listado sobre la diversidad de hongos dentro del territorio de la Estación Biológica de Torretes-Font Roja.

\section{DESARROLLO DE LAS II JORNADAS}

L.as Jornadas se inauguraton con una exposición fotogrifica de hongos $y$, con las recolecciones de material fúngico del día de actividades de campo, se amplió el muestratio de hongos con material fresco.

Tras b inauguración de las Jornadas, se ralizó un ciclo de cuatro conferencias:

1. "Introducción al mundo de los hongos": a cargo del Lodo. Pep Cantó, donde se destacaron las características propias de los hongos y se enumeraron las especies mís comunes de ecosistemas mediterrineos de la Península Ibérica.

2. "Relaciones beneficiosas entre bongos y plantas: Las micorrizas": por el Dr. Mario Honrubia, quien expuso la importancia de esta simbiosis en los ecosistemas.

3. "Ecologita de los hongus": presentada por el Dr. Alonso Verde con el objetivo de reseñar las adaptaciones al medio que han desarrollado estos organismos. 
4. "Niscales, Echlata-sings, Rovedlons i Petontsos: Las delicias del bosgue meditemineo": conducidia por el Ledo. José Fajardo y centrada en las especies comestibles del género Lactarises.

\section{VISITA A LA ESTACIÓN BIOLÓGICA DE TORRETES-FONT ROJA}

Se realizó una salida de campo a la Estación Biológica de Tortetes-Font Roja con el propósito de aprender buenas pricticas en L recolección de setas, su uso y conservación. Se repartió una ficha a cada participante para que se completaran el nombre $y$ la ecologia de las especies recolectadas y de este modo iniciar el inventario de hongos de la Estación (Foto 1).

Con la primera campaña de recolección de hongos, se han identificado alrededor de 30 especies de hongos ligados a estas comunidades. La mayor parte de éstos presentan un marcado caricter termófilo, (LLAMAS ef al., 2003) dentro del contexto tmediterríneo de la Perínsula Ibérica, siendo además típicos de los bosques y matorrales de suelos calizos. De todos los hongos catalongados cabe destacar los siguientes:
La mayor parte de las setas identificadas son comestibles, de entre ellas cabe destacar la presencia de Lactarius sangraifture e Hodnun albidom. La primera, conocida como 'rovelló o "eschata-sangs' es muy apreciada por su elevado valor culinario. Es la expecie más apreciada en nuestras comarcas tal y como senalan GARCIA et al, 2002, debido a que la firmeza de su carne permite cocinarlos de muchas maneras. La segunda, conocida popularmente como 'Hengua de vaca', 'lengua de gato' o 'gamuza', ex otra especie también muy valorada en gastronomia.

Especies raras:

- Muczlago crustacea P. Micheli ex F.H. Wigg. Es un mixomicete citado en varias localidades del sureste peninsular (Almería, Albacete $y$ sobretodo en Valencia), pero en Alicante sólo se tiene referencias de éste en Alooy por OL. TRA (1997) sobre lastón, según los datos del Sistema de Información Micolóngica Ibérica en Linea (SIMIL).

- Clitacybe alexandri (Gillet) Kontad. Especie rara, que ha sido citada solamente en dos localidades del Parque Natural de La Font Roja (BLANCO $c t d$ d, 2006) y con poca tradición culinaria en nuestras comarcas (Foto 2).

\begin{tabular}{|c|c|c|}
\hline NOMBRE CIENTIFICO & $\begin{array}{c}\text { NOMBRE } \\
\text { VERNÁCULOO }\end{array}$ & ECOLOGIA \\
\hline Geastram nanum Pers. & 'estrella de tierra' & $\begin{array}{l}\text { MATORRALES Y CLAROS } \\
\text { DE BOSQUE }\end{array}$ \\
\hline Stieroderna verrucosson (Bull.:Pers.) Pers. & & ENCINARES \\
\hline Tricholome scalpturnttum (Fr.) Quel. & 'fredolic de carrasca' & ENCINARES \\
\hline Hygrophorus nussula (Sch.Fr.) Quél & 'carlet' & ENCINARES \\
\hline Lactarias sanguifusus (Paulet:Fr) Fr. & 'esclata-sang' & PINARES TERMOFFILOS \\
\hline Suillus mediternaneensis (Jack. \& Blum) Redeuihl & & PINARES TERMÓFILOS \\
\hline Chroogomphes rutrilus (Schaeff.:Fr.)G.K. Miller & & PINARES TERMÓFILOS \\
\hline Mycend vulgaris (Pers.Ft.) Quel. & & PINARES TERMÓFILOS \\
\hline Hydnum albidun Peck. & 'tlengua de vaci'. & PINARES TERMÓFILOS \\
\hline
\end{tabular}




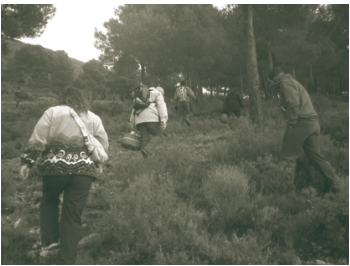

Foto 1s Visita a La Estación Biológica Torretes-Font Roji, donde se recolectó material para stu posserior identificación.

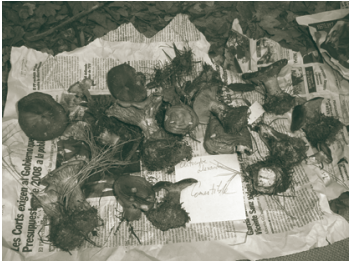

Foto 24 Clitocybe alearndfij respectivamente, una especie rara encontrada en la Estación. 
La experiencia de las II jornadas Micológicas ha sido muy positiva ya que tanto la parte más teórica, como b salida de campo y expecialmente L exposición, han tenido una gran repercusión local (más de 1.260 asistentes), contribuyendo muy positivamente a la divulgación del conocimiento de estos seres vivos. Debido a la gran acogida del evento y al interés despertado entre la población por los hongos $y$ su entorno, se acordó constituir en un futuro muy ptóximo la Acociación Micológion lbense. Ademis, se proyectarín nuevas campañas de muestreo durante los proximos meses, especialmente en primavera y otono, con el fin de completar el catálogo de hongos de la Estación Biológica de Torretes-Font Roja.

\section{BIBLIOGRAFIA}

BLANCO, D. FAJARDO, J.. VERDE, A. \& RODRIGUEZ, C. A. 2006. 100 setas de la provincia de Albacese. Instituto de estudios albacetenses -Don Juan Manuel* de la Excma. Diputación de Albacete. $257 \mathrm{pp}$.

GARCLA, F., CONCA, A. \& MAHIQUES, R. 2002. Bolets del Pare Natumil del Catruester de la Font Roja. Caja de Ahorros del Mediterrineo. $267 \mathrm{pp}$.

LLAMAS, B. \& TERRÓN, A. 2003. Athas fotogntfrco de los hongos de La Peninssula lberica. Celarays editorial. $547 \mathrm{pP}$. 